\title{
OS BLOCOS ASIÁTICOS E O RELACIONAMENTO BRASIL-ÁSIA
}

\author{
Henrique Altemani de Oliveira
}

\begin{abstract}
Resumo: Até pouco tempo não se podia falar em relações brasileiras com a Ásia, já que estavam basicamente restritas ao relacionamento com o Japão. Somente na década de 90 são ampliadas as relações com a Coréia do Sul, Sudeste Asiático, além da China. Assim, o relacionamento brasileiro com os blocos asiáticos restringe-se às tentativas de aproximação do Mercosul com a Asean, adquirindo agora maior intensidade política através do processo de institucionalização do relacionamento entre Ásia e América Latina com o Focalal.

Palavras-chave: bloco asiático; relações Brasil-Ásia; Focalal.
\end{abstract}

Abstract: Until recently, the only Asian country with which Brazil had any significant relations was Japan. Only in the 1990's was this scope widened to include South Korea, Southeast Asia and China. Up until now, the relationship between Brazil and the Asian blocks has been limited to Mercosul's overtures to Asean. This relationship is currently gaining in political intensity through the institutionalization of the relationship between Asia and Latin America, through Focalal.

Key words: Asian block; Brazil-Asia relations; Focalal.

$\mathrm{N}$ o momento em que, devido às dificuldades de acordo entre as principais potências na Organização Mundial do Comércio (OMC), as perspectivas de integração regional aparentam estar na agenda dos mais diferentes Estados, a presente análise procura refletir sobre o relacionamento brasileiro com as instituições asiáticas de integração regional.

A reflexão parte da premissa de que os principais atores internacionais (Estados Unidos, Japão/Ásia e Alemanha/ União Européia) estão num processo de disputa pelo poder internacional, no qual interagem não só as variáveis econômicas, como também as estratégicas. Assume-se a pressuposição da existência de uma íntima relação entre as variáveis econômicas e estratégicas como garantia de um continuado desenvolvimento econômico mundial. "Um inter-relacionamento interativo e sinérgico desenvolveu-se entre economia, política e segurança militar, não podendo ser significativamente separado: paz é precondição para a prosperidade e uma criativa diplomacia para gerenciar rivais econômicos e relações comerciais no mercado global é, por sua vez, precondição para uma paz duradoura" (Kegley, 1998:7).

Esse processo acaba incentivando, de um lado, o desenvolvimento de mecanismos regionais e, de outro, a formatação de alianças entre grupamentos regionais, tendo em vista a disputa pelo poder internacional.

Dessa forma, em primeiro lugar, serão analisadas as tentativas de formatação de blocos econômicos asiáticos, considerando-se que a região, por características internas, estaria muito mais propensa a esquemas de cooperação regional do que de estabelecimento de blocos propriamente ditos. Mas que, de outro lado, a crise asiática vai suscitar uma série de questionamentos sobre a região, os atores e seu papel no sistema internacional, induzindo à necessidade de definição de um esquema de bloco regional reativo aos já estabelecidos (UE - União Européia, Nafta North American Free Trade Agreement) ou em negociação (Alca - Área de Livre Comércio das Américas).

Em segundo lugar, será avaliado o atual relacionamento brasileiro com a Ásia, ponderando-se que historicamente se apresentava quase que integralmente restrito às relações econômicas com o Japão, com o acréscimo da relação política com a China a partir da metade dos anos 70. Apenas na última década do século passado, o relacionamento é ampliado e diversificado com a inclusão de novas parcerias.

Por fim, algumas considerações sobre as novas perspectivas de integração na Ásia e as possibilidades de in- 
tegração com o Brasil ou com o processo regional sulamericano.

Em decorrência da imprecisão do termo Ásia, a região que estará sendo abordada corresponde à Ásia-Pacífico, ou seja, o Leste Asiático (Japão, China, Hong Kong, Taiwan, Coréia do Sul e do Norte), o Sudeste Asiático (Indonésia, Malásia, Tailândia, Filipinas, Cingapura e Brunei) e outros países da região, como Vietnã, Laos, Camboja e Myanmar.

\section{OS PROCESSOS DE INTEGRAÇÃO NA ÁSIA}

A primeira iniciativa asiática concreta de desenvolvimento de um esquema regional de cooperação ou de integração, no plano econômico, surgiu em 1965, com a formalização da proposta apresentada pelo professor japonês Kiyoshi Kojima de criação de uma área de livre-comércio (Pafta - Pacific Asian Free Trade Area).

A motivação para essa primeira tentativa decorreu, entre outros fatores, dos receios do crescimento dos blocos regionais e da sensação de que poderiam criar entraves para o acesso ao mercado mundial. "A motivação original foi a preocupação japonesa de que a formação do Mercado Comum Europeu e os esquemas de livre-comércio na América Latina e em outros lugares estavam sinalizando para uma ruptura da economia mundial para blocos regionais, deixando o Japão de fora" (Arndt, 1990:563).

A proposta previa como membros plenos Estados Unidos, Japão, Canadá, Austrália e Nova Zelândia, com a possibilidade dos países em desenvolvimento da região aderirem como membros associados. No entanto, essa proposta não foi bem aceita no Sudeste Asiático devido à ênfase na forte presença ocidental, e, na realidade, o fator fundamental para seu fracasso foi a indisposição dos Estados Unidos em participar de esquemas de cooperação regional que pudessem afetar interesses americanos.

Ainda que não tenha obtido êxito formal, a proposta do professor Kojima, como reflexo de uma preocupação regional sobre as questões econômicas, propiciou o desenvolvimento de uma série de conferências com o objetivo de refletir sobre as possibilidades de cooperação regional. É necessário frisar que essas conferências, as quais vão caracterizar o processo asiático, abandonam completamente as perspectivas de área de livre-comércio e vão se concentrar especificamente nas questões de cooperação, e mesmo assim entendendo-se cooperação não como integração, mas como coordenação.

É exatamente essa idéia de coordenação de políticas econômicas que vai gerar as seguintes séries de conferên- cias: Pacific Trade and Development Conference (Paftad); Pacific Basin Economic Council (PBEC) e Pacific Economic Cooperation Conference (PECC).

Peter Drysdale, acadêmico australiano e incentivador da Paftad, define essas conferências como "privadas no sentido de que são convidados a título pessoal economistas de diferentes países do Pacífico. Os participantes não-acadêmicos não são representantes de seus governos nem de organizações internacionais, sendo convidados por sua capacidade profissional privada. Os participantes provêm principalmente do setor acadêmico e muitos tiveram uma experiência política importante no governo. As reuniões destinam-se, primeiramente, à consideração e ao exame dos aspectos de política econômica de importância para os países do Pacífico. Essa é a finalidade das análises e textos apresentados. Focalizar as políticas econômicas é o que marca a diferença em relação à pesquisa econômica pura $\mathrm{e}$ sua contribuição vai auxiliar e complementar as daqueles que aplicam na prática tais políticas, na esfera dos governos e no mundo dos negócios" (Legorreta, 1994:7).

Da mesma forma que a Paftad, o PBEC, constituído em 1967, é uma organização não-governamental operando como uma rede de relações comerciais, com o objetivo de estabelecer um ambiente mais favorável para os negócios na região. Em outros termos, trabalha na perspectiva de coordenação de políticas que possam influenciar governos e organizações internacionais na manutenção de políticas de mercados abertos e na diminuição de barreiras ao comércio e ao investimento.

No final dos anos 70, enquanto nos Estados Unidos, com base no relatório Patrick-Drysdale, encomendado pelo Senado norte-americano, crescia a expectativa de implementação de uma Comunidade do Pacífico, no Japão sedimentava-se a perspectiva de que, antes de uma organização voltada para a integração econômica, seria necessária a superação das diversidades culturais e ressentimentos históricos.

Assim, dentro dessa visão japonesa, em 1980, iniciase a série PECC, com a presença de delegações de 11 países: os cinco desenvolvidos (Estados Unidos, Japão, Canadá, Austrália e Nova Zelândia), os cinco membros da então Asean - Association of Southeast Asian Nations (Malásia, Indonésia, Cingapura, Filipinas e Tailândia) e a Coréia do Sul. Cada delegação tem uma composição tripartite: um representante acadêmico, um do setor privado e um do setor governamental a título privado.

As conferências PECC "têm podido levar a cabo amplo e profundo trabalho exploratório dos mais diversos 
aspectos das relações intrapacíficas, terminando por pesar nas políticas governamentais da região. (...) Destruíram muitas das ilusões em torno da rápida formalização da cooperação econômica no Pacífico mas, por outro lado, vão mantendo vivo, e até robustecendo, o ideal correspondente. Têm a seu crédito duas importantes realizações: a lenta elaboração de vasta malha de relacionamentos pessoais entre entusiastas oriundos dos quatro cantos do grande oceano e o acúmulo de impressionante massa de informações sobre as necessidades e possibilidades da área" (Oliveira, 1995:104-105).

Enquanto essas iniciativas de cooperação se processam no Leste Asiático, detectam-se diferentes propostas voltadas para o campo da segurança no Sudeste Asiático, desde o final da Segunda Guerra Mundial, culminando com a estruturação da Asean, em 1967. A criação da Asean só foi possível após a solução parcial das reivindicações territoriais envolvendo principalmente Indonésia, Malásia e Filipinas; da separação de Cingapura da Federação Malaia; e a instalação de governos mais pró-americanos na Indonésia com a deposição de Sukarno em 1965 e, nas Filipinas, com a posse de Ferdinando Marcos em 1966.

Apresentada como tendo o objetivo de promover o crescimento econômico, a Asean, na realidade, tinha a missão de evitar o avanço do comunismo. "Durante os primeiros 20 anos de sua existência, Asean foi essencialmente uma organização política antes do que econômica. Os objetivos políticos predominaram em larga medida por causa da ameaça comum interna dos grupos guerrilheiros comunistas, da ameaça externa do Vietnã comunista e os imperativos de manter boas relações dentro do Sudeste Asiático não-comunista de forma a ser capaz de estabelecer e manter a estabilidade regional" (Stubbs, 2000:300).

Concisamente, Gutiérrez (1993) aponta que a Asean apresenta três fases desde sua criação, sendo a primeira correspondente ao processo de manutenção da segurança regional, evitando-se a transformação dos regimes políticos nacionais em comunistas e colaborando para a diminuição dos conflitos internos, bem como para a estabilidade entre fronteiras.

A segunda fase, com maior ênfase nos anos 80 , abrange o período em que o Sudeste Asiático se insere no processo de desenvolvimento econômico asiático, por intermédio da transferência de empresas e investimentos tanto do Japão quanto dos Tigres Asiáticos.

A terceira fase, já no pós-guerra fria, representa um novo direcionamento de seus objetivos. De um lado, o lançamento do projeto de estabelecimento de uma área de livre-comércio (Asean Free Trade Area - Afta) em 1992, com previsão de redução tarifária até sua efetivação em 2008. E, de outro, a ampliação da Asean em seu papel de mecanismo garantidor da segurança estratégica, não só restrito ao Sudeste Asiático, mas incluindo o total da ÁsiaPacífico através do ARF - Asean Regional Forum.

Esse Fórum Regional (ARF) foi institucionalizado em 1993 com caráter intergovernamental para discussão de questões políticas e de segurança. No início, foram incluídos como participantes do ARF os membros da Asean (Brunei, Cingapura, Malásia, Indonésia, Filipinas e Tailândia), seus sete maiores parceiros comerciais (Estados Unidos, União Européia, Japão, Canadá, Coréia do Sul, Austrália e Nova Zelândia), dois convidados (China e Rússia) e três observadores (Vietnã, Laos e Papua-Nova Guiné).

A inserção do ARF dentro da Asean decorreu, entre outros, do fato de ela ser a única organização na região com um fórum de diálogo estabelecido e de já ter uma forte importância na arquitetura de segurança regional através dos princípios contidos no Tratado de Amizade e Cooperação (pelo qual se assegura que nenhum membro procurará resolver suas disputas pelo uso da violência).

Utilizando o mesmo canal da Asean, mas muito mais em decorrência da experiência das conferências Paftad, PBEC e PECC, criou-se a Apec (Asia-Pacific Economic Cooperation forum) com um caráter essencialmente econômico e como um fórum informal em resposta ao aumento do regionalismo econômico e, conseqüentemente, para discussão de questões econômicas e ampliação da cooperação regional.

Constituída em 1989 com 12 membros (Austrália, Canadá, Estados Unidos, Japão, Coréia do Sul, Nova Zelândia e os seis membros da Asean - Indonésia, Malásia, Tailândia, Filipinas, Brunei e Cingapura), a Apec conta hoje com 21 membros. ${ }^{1}$

De sua criação até 1992, a Apec caracteriza-se pela ausência de propostas concretas que pudessem levá-lo a ter uma atuação mais ativa no contexto regional. De acordo com Donald Crone (1992), essa rede organizacional não emergiu rapidamente nem está definida ainda: antes de sua formação, algumas questões foram levantadas e, em princípio, permanecem, em torno de sobre o que cooperar e com quem.

A primeira questão seria a participação dos Estados Unidos, de uma forma genérica percebida como fator de estabilidade para a segurança regional e de instabilidade especificamente para o comércio e para outras áreas correlacionadas, a partir de suas constantes críticas quan- 
to às condições sociais dos trabalhadores e aos direitos humanos e pressões sobre direitos intelectuais. Deve-se notar que a proposta inicial excluía os Estados Unidos e o Canadá, primeiramente, devido às mudanças no protecionismo norte-americano em relação ao Pacífico e, em seguida, devido a um posicionamento contrário à participação dos Estados Unidos num mesmo organismo com o Japão, temendo-se que seu relacionamento bilateral monopolizasse as atividades da organização.

$\mathrm{Na}$ realidade, essa questão da presença norte-americana em organismos regionais asiáticos estava igualmente na base da proposta do Primeiro-Ministro da Malásia (Mohamad Mahatir) sobre a criação dos Eaeg (East Asian Economic Grouping). O Eaeg previa somente a participação de Estados asiáticos, excluindo tanto os Estados Unidos, quanto o Canadá, Nova Zelândia e Austrália. Previa igualmente que o Japão se predispusesse a liderá-lo.

De outro lado, e favoravelmente à presença dos Estados Unidos, havia o receio de predominância do Japão. Nesse sentido, Malásia e Tailândia preocupavam-se com o predomínio norte-americano, enquanto Cingapura achava que a ausência dos Estados Unidos e a ameaça de um bloco do yen desestimularia a proposta australiana. Já a Indonésia questionava se um ou outro isoladamente teria condições de liderar o processo, raciocinando que a presença de ambos seria favorável às economias abertas da região. Porém, os Estados Unidos conseguiram sua participação devido às suas pressões e ao pedido japonês de sua inclusão.

A proposta inicial de Hawke (Primeiro-Ministro australiano) para o estabelecimento da Apec era vista como uma resposta à emergência de blocos regionais, principalmente na Europa e na América, tendo Sueo Sudo (1994) subentendido que essa divergência de posições decorria principalmente de fatores regionais, como o surgimento de um novo regionalismo, a reinserção do Sudeste Asiático na era pós-hegemônica e a dificuldade do Japão em assumir um novo papel tanto no contexto regional quanto no internacional.

Desde sua constituição e, principalmente, nesse primeiro momento, está bem patente a perspectiva de ser um mecanismo que está buscando seu sentido, isto é, decorre do reconhecimento da necessidade e do interesse de desenvolvimento de consultas e cooperação em âmbito regional, porém com um caráter deliberadamente vago.

Independentemente dessa aparência de indefinição de objetivos e de estratégias, pode-se visualizar a Apec como o resultado de um processo de interação das perspectivas americanas e asiáticas do Pacífico, dentro do contencioso econômico-comercial entre o Japão (compreendendo a economia asiática) e os Estados Unidos.

Em outros termos, os momentos iniciais da Apec deixam bem claro que sua proposta não é de estabelecimento de um mecanismo de integração econômica nos moldes da UE, mas, muito mais, de um fórum de coordenação política de questões econômicas regionais. "Quando o Primeiro-Ministro australiano Bob Hawke propôs o estabelecimento da Apec, em 1989, ele tomou como modelo a OCDE, a Organização para a Cooperação e o Desenvolvimento Europeu, o grupo baseado em Paris que promove a coordenação de políticas econômicas domésticas e internacionais entre seus Estadosmembros. O principal papel da OCDE é aumentar a transparência, coletando e divulgando informações sobre as políticas de seus membros. A OCDE não é um fórum para negociações comerciais e a Apec inicialmente também não estava desenhado para sê-lo" (Ravenhill, 2000:321).

No entanto, a partir de 1993, na reunião de Seattle, a perspectiva de liberalização comercial torna-se a peça-chave da agenda da Apec. Na reunião de Seattle, presidida pelos Estados Unidos, procurou-se estabelecer, em primeiro lugar, uma Estrutura de Comércio e Investimento para futura liberalização de comércio e investimento. Em segundo, o Grupo de Personalidades Eminentes, que em 1992 tinha recebido a incumbência de preparar a institucionalização da Apec, apresentou um relatório (Para uma comunidade econômica da Ásia-Pacífico) propondo que a Apec acelerasse a cooperação econômica com vistas ao estabelecimento de um regime de livre-comércio e de investimento na região. E, em terceiro, procurou-se instrumentalizar a reunião para se obter um consenso mútuo de apoio à conclusão da Rodada do Uruguai do GATT.

Na reunião na Indonésia, em 1994, deu-se seqüência ao objetivo de estabelecimento da área de livre-comércio, com um cronograma de adaptação até 2010 para os países desenvolvidos e até 2020 para os em desenvolvimento. Permaneceu, no entanto, a questão de definição de quais membros eram desenvolvidos e quais estavam em desenvolvimento.

Entretanto, essa disposição para definição de uma área de livre-comércio decorria precipuamente das intenções norte-americanas e dos países ocidentais membros, sofrendo uma velada oposição dos membros asiáticos, principalmente do Japão e da Malásia. "Os membros asiáticos procuram evitar a evolução da Apec para um outro fórum no qual os governos ocidentais possam atacar suas políticas comerciais. Além disso, dada sua dependência comercial 
da Europa Ocidental como da América do Norte e outras partes da Ásia, eles se opõem radicalmente a qualquer mudança para a Apec se transformar numa área comercial preferencial (na realidade, um de seus interesses no estabelecimento do grupo, no momento em que as negociações na Rodada Uruguai do GATT estavam estagnadas, era diminuir as possibilidades de fragmentação da economia global em blocos comerciais rivais)" (Ravenhill, 2000:321).

Assim, já na próxima reunião, sob liderança japonesa, 1995 em Osaka, a perspectiva de transformação da Apec numa área de livre-comércio é praticamente descartada. Essa reunião vai se caracterizar pela retomada da via asiática, pela definição da idéia de regionalismo aberto, segundo o qual as vantagens tarifárias que os membros da Apec se concederem mutuamente devem ser estendidas a todos os não-membros, via cláusula da Nação Mais Favorecida e sem exigências de contrapartida.

Além disso, flexibilizou o disposto na reunião de Bogor sobre os prazos de liberalização comercial, deixando a cargo de cada país-membro decidir sobre os prazos e o calendário para implementação de seus compromissos de liberalização.

\section{AS RELAÇÕES BRASILEIRAS COM A ÁSIA}

Em seu atual projeto de inserção internacional, o Brasil delega à região asiática um espaço especial, considerando-se a grande demanda por investimentos e por acesso a tecnologias de ponta, bem como por um mercado com alta capacidade de consumo. Por sua vez, o Brasil levanta interesses na Ásia por se caracterizar como uma importante fonte supridora de matérias-primas, principalmente produtos alimentícios e insumos básicos. Nesse sentido, à medida que a Ásia se dinamiza e se especializa em produtos manufaturados, é mantido ou ampliado o interesse na importação de produtos básicos do Brasil.

A presente análise aponta que até a década de 70 o relacionamento brasileiro com a Ásia restringia-se basicamente às relações com o Japão, e à aproximação, de caráter mais político, com a República Popular da China na metade dos anos 70. Mesmo esse estrito relacionamento sofre uma retração com a sucessão de crises nos anos 80 , retomando força na década de 90 .

Nessa última década, a retomada e ampliação do relacionamento com a Ásia adquire novo vigor pela maior presença tanto da Coréia do Sul e dos países do Sudeste Asiático, quanto da China que, em decorrência de seu desenvolvimento acelerado, não é mais apenas um ator político, mas um forte mercado consumidor além de fornecedor. Essa retomada tem clara conotação econômica, mas também é influenciada pela disputa comercial entre os países desenvolvidos e a proposta de criação da Alca, por muitos entendida como uma modalidade de protecionismo regional, com entraves para a inserção de atores externos.

Assim, até quase o final do século XIX pode-se afirmar que não havia qualquer tipo de relacionamento entre o Brasil e a Ásia. No que se refere ao Japão, por exemplo, somente com a Restauração Meiji (1867) é que o Japão vai sofrer uma série de modificações estruturais que possibilitam o estabelecimento do Japão moderno e também uma abertura para o exterior.

Em decorrência da Restauração Meiji, a economia japonesa sofre um processo de desestabilização provocando fluxos migratórios inicialmente para o Havaí e a Costa Oeste dos Estados Unidos. Do lado brasileiro, com a abolição da escravidão em 1888 e o crescimento rápido da lavoura cafeeira no Estado de São Paulo, tornou-se necessária a ampliação da migração de mão-de-obra externa.

Dessa forma, o relacionamento bilateral entre o Brasil e o Japão inicia-se com a vinda de migrantes para o trabalho nas lavouras cafeeiras. A base legal para esse relacionamento é criada, primeiramente, pela assinatura do Tratado de Amizade, Comércio e Navegação em novembro de 1895 e, depois, pelo estabelecimento de companhias que trabalhavam especificamente no recrutamento e transporte de imigrantes.

Pode-se notar que inicialmente a opção era por mãode-obra chinesa, motivando o deslocamento de uma missão brasileira para a China em 1879. Mesmo com a nãoconcretização dessa corrente migratória, pela proibição formal da China em permitir emigração para o Brasil, os dois países assinaram o Tratado de Amizade, Comércio e Navegação em 1881, com a abertura de um consulado brasileiro em Xangai em 1883.

A chegada do navio "Kosato Maru”, em 1908, dá início à imigração japonesa ao Brasil, tendo um crescimento significativo até 1934 quando a nova Constituição brasileira limita o fluxo migratório, o qual praticamente se interrompe com a Segunda Guerra Mundial e é retomado somente após 1955. Já com a China, os contatos bilaterais foram escassos em decorrência da sucessão de conflitos internos e externos que afetaram esse país no final do século XIX e na primeira metade do século XX. Com a vitória de Mao Zedong em 1949, o Brasil rompe as relações diplomáticas.

Dessa forma, é interessante ressalvar que o relacionamento entre Brasil e Ásia até a década de 50 ficou quase 
unicamente restrito ao campo sociocultural representado pelo fluxo migratório japonês. E que nas décadas de 50 a 70 não se pode, então, pensar propriamente num relacionamento Brasil-Ásia. Apesar de presente em discursos, principalmente a partir da política externa independente no governo Jânio Quadros, constata-se, na realidade, somente uma interação, no plano multilateral, de construção de uma agenda política comum a países em desenvolvimento no processo de defesa de instauração de uma nova ordem econômica internacional.

Sukarno, em 1959, foi o primeiro presidente asiático a visitar o Brasil. E, em maio de 1961, foi assinado um acordo bilateral econômico. Excluindo esses dois eventos, pode-se afirmar que inexistiu, até a década de 80 , um relacionamento concreto entre os dois países, ou mesmo com o Sudeste Asiático. Na realidade, a Indonésia passa a compor o imaginário político no que se refere ao estreitamento de vínculos com o mundo afro-asiático, dentro dos pressupostos da política externa independente.

A intensificação das relações com o mundo afro-asiático seria conseqüência da necessidade de autodeterminação não só nacional, mas também do contexto afro-asiático com vistas à superação mútua do subdesenvolvimento. Nesse sentido, as perspectivas de inter-relacionamento mantêm-se no contexto do espirito de Bandung (conferência realizada na Indonésia em 1955 e que daria origem ao Movimento dos Não-Alinhados), sem que se chegue a uma definição objetiva.

Dessa forma, nesse período, o relacionamento brasileiro com a região asiática esteve restrito às relações com o Japão, considerando-se ainda que decorria basicamente da iniciativa japonesa. Nesse sentido, aponta-se a ocorrência de dois ciclos de investimento direto japonês no Brasil e que condicionam igualmente o fluxo comercial.

O primeiro ciclo, na segunda metade da década de 50 , esteve claramente relacionado à constituição de uma infraestrutura comercial, a cargo de trading companies japonesas. Seu objetivo era assegurar fontes regulares de fornecimento de matérias-primas, bem como firmar-se como exportador de manufaturados. Assim, as primeiras empresas que se instalam no Brasil, nesse período, são do ramo têxtil e de comercialização. Embora sem muita expressão econômica internacional e em decorrência de sua extrema fragilidade devido à escassez de matérias-primas em seu território, o Japão investe pesadamente no projeto de aço da Usiminas.

O segundo ciclo, nos anos 70, coincide com os anos dourados do milagre econômico brasileiro, com a conso- lidação do Japão como potência econômica e com a valorização do iene. Além da idéia de desenvolvimento e manutenção de fornecedores seguros e estáveis, o Brasil, nesse momento, mostra-se atrativo em decorrência de seu crescimento acelerado. Note-se que a maior parte desses investimentos foi realizada em associação com empresas estatais indicando, de um lado, uma possível convergência de interesses entre o Estado japonês e o brasileiro e, de outro, a busca de maior estabilidade política e econômica aos investimentos realizados.

Como emblema dessa convergência entre os dois Estados aponta-se, por exemplo, a estratégia utilizada pelo Japão de incentivo ao desenvolvimento da produção de soja no Brasil. Quando os Estados Unidos, em 1973, decide instrumentalizar o mercado de soja como uma arma em relação ao Japão, inicia-se o investimento japonês no Programa de Desenvolvimento do Cerrado (Prodecer), fazendo com que o Brasil, de produtor marginal, se transformasse, já no início dos anos 80 , no segundo maior produtor de soja, logo após os Estados Unidos.

Denota-se, assim, certa complementaridade entre os dois países: fornecimento de matérias-primas em troca de investimentos e fornecimento de produtos industrializados. A relação comercial do Brasil com o Japão, no entanto, mantém-se no esquema tradicional de colocação de produtos básicos, enquanto a tendência geral, na pauta de exportações brasileiras, era de ampliação da venda de produtos manufaturados.

Essa complementaridade nipo-brasileira sofre, porém, um processo de retração a partir do início dos anos 80 , em decorrência, por um lado, da diminuição da importância da garantia de fornecimento de matérias-primas, seja pelo aumento da oferta como pela queda dos preços reais e, por outro, pela aceleração da crise econômica brasileira, revertendo as expectativas de que a economia brasileira continuaria crescendo a ritmo acentuado.

Essa crise vai inclusive propiciar o surgimento do fenômeno chamado dekassegui, ou seja, o estabelecimento de um fluxo migratório de descendentes de japoneses para trabalho no Japão. Os dekasseguis, atualmente em torno de 250 mil, passaram a ser um fator importante no relacionamento nipo-brasileiro como fonte significativa de fluxo de capitais.

O Brasil só retoma relações diplomáticas com a China em 1974, num momento em que o país, em decorrência de seu desenvolvimento econômico e de uma conjuntura internacional favorável, está diversificando suas parcerias internacionais e buscando uma inserção mais compe- 
titiva. Dentro de seu projeto de política externa, com forte atuação nos fóruns multilaterais e com ênfase nas teses do Terceiro Mundo, a reaproximação com a China era fundamental para dar credibilidade e legitimidade à ação brasileira.

Assim, ainda que de início tenha implicado um aumento dos fluxos comerciais, as relações sino-brasileiras vão se manter mais restritas ao campo político-diplomático realçando as similaridades de posicionamentos comuns perante o sistema internacional. Somente na década de 90 , com a abertura econômica brasileira e com a maior inserção chinesa, processa-se uma maior aproximação comercial entre os dois países, ainda que prioritariamente se resguarde a importância do relacionamento político. Por esse posicionamento e considerando-se ainda o potencial de aprofundamento das relações em longo prazo, a expressão parceria estratégica, cunhada por Zhu Rongji em 1993, passa a ser enfaticamente utilizada.

No plano político, um ponto central da agenda internacional dos dois países refere-se às suas pretensões em relação à $\mathrm{OMC}$ e à Organização das Nações Unidas (ONU). A China utiliza-se de seu assento permanente no Conselho de Segurança para se aproximar dos países em desenvolvimento e nesse sentido acena com a possibilidade de apoiar o interesse brasileiro em aceder ao Conselho de Segurança. De outro lado, o Brasil, em seu posicionamento por regras mais justas no comércio, internacional e defendendo o sistema multilateral de comércio, apóia a entrada da China na OMC.

A parceria estratégica ganha um contorno mais definido na área de cooperação técnica e científico-tecnológica. Nessa área encontra-se o mais ambicioso projeto das relações entre os dois países: o trabalho conjunto para o desenvolvimento de satélites de sensoreamento remoto, tendo sido lançado em 1999, com sucesso, o primeiro satélite. O projeto, inclusive, foi ampliado, planejando-se produzir mais dois satélites, além dos dois inicialmente previstos. Os satélites permitirão aos dois países uma independência na área de imagens por satélites, possibilitando-lhes inclusive passar de usuários a exportadores desse tipo de serviço.

Já as relações com a Coréia do Sul e com o Sudeste Asiático adquiriram relevância somente a partir dos anos 90, dentro do contexto de reestruturação do sistema internacional pós-guerra fria. A crescente participação coreana no comércio brasileiro parece ter sido reforçada pelo fato de os conglomerados coreanos (chaebol) mostrarem-se mais agressivos na conquista de mercados seja na Améri- ca Latina, seja no Brasil, procurando suplantar o papel tradicional desempenhado pelo Japão. Sua ação parece estar orientada pelo objetivo de formação de redes de distribuição e de comercialização, criando possibilidades de investimentos diretos como base para uma integração produtiva em setores de manufaturados.

O Sudeste Asiático, por seu desenvolvimento econômico acelerado e pelo fato de estar integrado através da Asean, passou a ser visualizado como um possível parceiro político e econômico, principalmente depois do estabelecimento do Mercosul. De qualquer forma e independentemente das respectivas crises financeiras, desenha-se a perspectiva de uma aproximação inicial mais de cunho político, para posterior crescimento do intercâmbio comercial.

Quando da visita do Secretário-Geral da Asean ao Brasil, em 1997, discutiram-se alternativas para uma maior aproximação entre Mercosul e Asean. Chegou-se à conclusão que seria pertinente desenvolver mecanismos para tornar mais concreta a prioridade política e, igualmente, superar as falhas de conhecimento recíproco. Com base na percepção desse distanciamento, concordou-se também que, no atual momento, não é objetivo o estabelecimento de uma área de livre-comércio entre as duas regiões.

Mesmo assim, houve um crescente aumento no intercâmbio comercial entre o Brasil e a Asean, demonstrando a potencialidade de maior estreitamento. No caso da Asean, assim como da China, chama igualmente a atenção a existência de imensas possibilidades quanto à prestação de serviços no desenvolvimento de infra-estrutura, em especial no campo energético e de transportes. Vale lembrar que recentemente a Companhia Brasileira de Projetos e Obras liderava o consórcio que venceu a licitação internacional para a construção da hidrelétrica de Bakun, na Malásia. No entanto, essa que seria a primeira grande obra de engenharia do Brasil na Ásia não foi ainda iniciada em função da crise asiática. No que se refere à construção da hidrelétrica de Três Gargantas, na China, apesar do reconhecimento da competência brasileira, a participação foi prejudicada pela dificuldade de obtenção de financiamento para a obra.

Em decorrência da retomada da atratividade do Brasil, de um lado, pela abertura do mercado e estabilidade financeira e, de outro, pela ampliação do mercado através do processo integrativo regional com o Mercosul, percebe-se claramente um crescente interesse asiático pelo Brasil. Esse interesse não é só econômico-comercial, mas igualmente político-estratégico em função da disputa por poder e por mercados que se processa na OMC e em outros fóruns multilaterais. 
De outro lado, o presente relacionamento econômicocomercial apresenta uma clara tendência de crescimento, principalmente pela diversificação dos parceiros comerciais, o que corresponde igualmente à constatação de que o Japão não constitui mais o único mercado asiático para os produtos brasileiros.

Em seu atual projeto de inserção internacional, o Brasil delega à região asiática um espaço especial. Entretanto, em decorrência de contradições internas e de conjunturas externas, não conseguiu ainda delinear as formas de atingir esse objetivo. O Japão continua mantendo um locus importante no relacionamento econômico-comercial, enquanto no político destaca-se o relacionamento com a China. A Coréia do Sul e o Sudeste Asiático, pelos respectivos processos de desenvolvimento econômico acelerado, passaram igualmente a ser visualizados como possíveis parceiros políticos e econômicos.

\section{NOVAS PERSPECTIVAS DE INTEGRAÇÃO NA ÁSIA E DE RELACIONAMENTO COM O BRASIL}

A crise asiática pode ser considerada como o momento de inflexão das políticas regionais asiáticas, a partir do momento em que passou a exigir uma maior atuação regional para encaminhamento de soluções para a crise em si. $\mathrm{Na}$ realidade, a crise desnudou as fragilidades regionais, demonstrando que a interdependência por si só não tem capacidade de manter a região isolada de instabilidades, como também que o processo de disputa por poder econômico entre Estados Unidos, União Européia e Japão não afeta só o Japão, mas acaba englobando toda a região, exatamente em função da forte interdependência regional.

Nesse sentido, retomam-se as expectativas de desenvolvimento de um processo de integração regional, com características essencialmente asiáticas, sem a participação de atores externos, podendo ser canalizado para estruturas institucionalizadas com o objetivo de encarar questões transnacionais comuns. Ou, mesmo, como uma resposta necessária à tendência de aprofundamento dos regionalismos europeu e americano.

No que se refere especificamente à esfera econômica, Funabashi aponta que o Japão estava acomodado com a metáfora dos flying geese, que ressaltava sua liderança no processo de desenvolvimento econômico asiático, ao mesmo tempo que o colocava como o principal interlocutor asiático com o resto do mundo. "Mas a visão do Japão sobre a Ásia e seu próprio papel nela está sendo desafiada pelas novas realidades econômicas: o crescimento da
China e seu desafio ao Japão; o rápido avanço da informação e o desenvolvimento das tecnologias de comunicação em outros países asiáticos, como a Índia, Cingapura e Coréia do Sul; o rebaixamento do Japão, de modelo do desenvolvimento asiático para um exemplo de confusão e paralisia; e o impacto da globalização na tradicional abordagem japonesa da ajuda externa como foco de investimentos externos governamentais para investimentos externos diretos privados. Outros países asiáticos estão se transformando em grandes atores econômicos na região e o Japão não é mais o único" (Funabashi, 2000-01:77).

Nesse sentido, com suas implicações na reivindicação de um posicionamento mais claro e cooperativo de recuperação regional e manutenção da competitividade internacional, a crise forçou a definição de novos papéis e o arranjo de novas alianças. Assim, no caso do Japão, pode-se perceber a pressão para uma maior atuação regional no encaminhamento de soluções para a crise. E a China, ao não se engajar numa desvalorização competitiva, procurou transmitir a imagem de um poder cooperativo e pacífico.

A reunião informal da Asean, em novembro de 1999, ressuscitou a idéia defendida em 1990 pelo Primeiro-Ministro da Malásia, Mahathir Mohamad, de institucionalização de um bloco regional, com características essencialmente asiáticas.

No entanto, agora, a reunião da Asean demonstra que ainda constitui uma força regional e que a adesão dos três líderes do Nordeste Asiático - Japão, China e Coréia do Sul -, constituindo o processo Asean +3 , reflete a tendência para uma crescente cooperação, especialmente em economia. A ênfase no reforço da cooperação econômica indica igualmente o cuidado em evitar eventuais discussões sobre questões políticas e de segurança.

Evidentemente, não é provável que um mercado comum asiático seja institucionalizado em curto prazo, levandose em consideração a persistência de profundas divergências históricas entre os principais atores. "Inimizades históricas permanecem profundas na região e não vão desaparecer da noite para o dia. Mas o principal fato é que a definição de objetivos mostra uma tendência para uma crescente integração da região, a qual se preocupa com a emergência de blocos em outras partes do globo, como o Nafta e a União Européia" (Ching, 1999:36).

Apesar dessas dificuldades, não se duvida que o processo pode contribuir para ampliação da mútua compreensão e confiança e uma mais durável estabilidade e paz no Leste Asiático. Mas, além disso, há o interesse dos três atores do Nordeste Asiático em atuar em conjunto com o 
Sudeste Asiático, mesmo que em função de uma disputa para ampliação do poder individual.

No plano da cooperação econômica, a presença do Japão mostra-se fundamental para transferir credibilidade a qualquer desenvolvimento do bloco, porque é um instrumento que possibilita uma atuação japonesa sem cobranças de seu passado.

Retoma-se ainda a idéia de que a proposta de um mercado comum sem a presença dos Estados Unidos tem significativa importância enquanto se busca a definição de uma identidade regional, na qual não só se aceita mas também se requisita a presença japonesa. Sob outra perspectiva, enquanto Asean +3 pode desempenhar um papel fundamental na aproximação dos atores regionais, pode igualmente ser visualizado como um entrave à liberalização do comércio internacional, num processo no qual a Ásia, com sua extrema dependência dos mercados externos, apresenta-se relativamente mais fragilizada.

"Entretanto, a provável institucionalização de um bloco econômico do Leste Asiático na próxima década enfrenta grandes obstáculos. Um contínuo constrangimento contra um bloco comercial asiático discriminatório é a dependência das economias regionais dos mercados de fora da Ásia. Ainda que a participação do comércio intra-regional tenha crescido rapidamente na década anterior à emergência da crise asiática, mais da metade de suas exportações ainda é direcionada para mercados de fora da região. $\mathrm{O}$ receio de que a institucionalização de um bloco asiático discriminatório possa provocar uma guerra comercial global, na qual as economias asiáticas poderiam ser as maiores vítimas, ainda preocupa muitas capitais" (Ravenhill, 2000:331).

Nesse sentido, o Relatório Brookings 2000-01 aponta a emergência de uma forte tendência para o multilateralismo na Ásia, considerando que, de um lado, propicia a reinserção dos principais atores regionais, enquanto, de outro, pode marginalizar o papel norte-americano nos campos econômicos e diplomáticos.

"Apesar dessas persistentes realidades, os Estados Unidos não deveriam rejeitar as tendências e os benefícios do multilateralismo na região. A maior utilidade dessas organizações pode ser aproximar os principais atores da região - particularmente China e Estados Unidos - de uma forma que possa regularizar os contatos e afastar desavenças, desconfianças e conflitos. Além disso, o impulso para encontrar soluções multilaterais ressoa de forma muito mais intensa do que anteriormente. Há tanto benefícios quanto perigos para os Estados Unidos nessa tendência. Nos pró- ximos anos, o desafio para os Estados Unidos será manter seu papel como responsável pela segurança regional, ao mesmo tempo que deve evitar ser marginalizado dos planos econômicos e diplomáticos" (Brookings, 2000-01:7-8).

Em conjunto com a atual disposição de estabelecimento de um mecanismo regional que possa propiciar melhores condições de desenvolvimento regional, assim como de inserção internacional, detectam-se dois instrumentos complementares que buscam exatamente manter e/ou ampliar os relacionamentos asiáticos com duas outras regiões: a União Européia e a América Latina.

O projeto Asem (Asia-Europe Meeting), uma iniciativa do Primeiro-Ministro de Cingapura, Goh Chok Tong, tem como objetivo estreitar os laços políticos, econômicos e culturais entre os dois continentes. Para a UE, a institucionalização do Asem, estrategicamente, tem o papel de ser um instrumento de aproximação política com a Ásia, com o objetivo precípuo de evitar que Estados Unidos possam se manter isolados na região. Em outros termos, a UE espera, com o Asem, ser um ator político regional, além de econômico, de forma que possa relativizar a importância que os Estados Unidos detêm na região.

O Asem, cuja primeira reunião foi em 1995, antes então da concordância no desenvolvimento do Asean +3 , tem como participantes asiáticos os membros da Asean, mais Japão, China e Coréia do Sul. Para o Japão, ainda que as diferentes questões a serem discutidas já estivessem embutidas no seu relacionamento bilateral com a UE, a importância do Asem está no fato de representar um diálogo inter-regional sem a presença dos Estados Unidos. Nesse sentido, note-se que Japão reagiu lentamente à proposta até ter ciência de que os Estados Unidos não se opunham ao encontro.

"Em adição aos óbvios benefícios econômicos, o desenvolvimento de futuras relações com a Europa ao nível de região para região era visualizado no Japão como oferecendo um contrapeso ao crescente papel ambivalente jogado pelos Estados Unidos na região. Essa linha particular de raciocínio está alicerçada na contabilidade contemporânea de estruturas econômicas tripolares baseadas no Japão (Ásia), UE (Europa) e Estados Unidos (Nafta). Acomoda os próprios interesses do Japão de desempenhar um maior papel internacional dentro de uma estrutura multilateral" (Gilson, 1999:737).

Mas, mais do que isso, começou-se a ter ciência de que o Asem poderia ser um instrumento de reaproximação com a Ásia e de uma forma em que não estivessem presentes os constrangimentos históricos, possibilitando um conta- 
to mais íntimo entre os diferentes Estados em torno de um objetivo comum. Nesse sentido, o processo em si colabora para construção e reforço de uma identidade asiática, ou, em outros termos, de um posicionamento asiático perante os outros agrupamentos políticos e econômicos.

"A originalidade do processo Asem reside em sua proposta fundamental de uma região contra a outra (ao contrário da Apec, ARF e a Conferência Pós-Ministerial da Asean). Posiciona, assim, dois corpos coerentes e externamente diferenciados cuja composição permanece altamente inquestionável dentro do Asem. Esta nova instituição promove um mecanismo inter-regional regular e coordenado que aproxima esta 'Ásia' e esta 'Europa'. Paradoxalmente, este diálogo inter-regional pode servir mais efetivamente para aumentar a cooperação intra-regional, porque pode mais claramente articular explicitamente a presença de uma Ásia vis-à-vis uma precisa e visível Europa. Como resultado, este mecanismo pode até mesmo induzir à criação de uma identidade regional asiática..." (Gilson, 1999:749).

Este crescente regionalismo pode ser canalizado para estruturas institucionalizadas com o objetivo de encarar questões transnacionais comuns. Ou, mesmo, visualizado como uma resposta necessária à tendência de aprofundamento dos regionalismos europeu e americano.

Da mesma forma que o Asem, o recente processo de aproximação entre Ásia e América Latina vai ter como ponto inicial uma proposta de Cingapura e vai englobar os países-membros da Asean mais o Japão, China e Coréia do Sul. Como proposta básica, trata-se de uma iniciativa com vistas a institucionalizar uma aproximação política de alto nível e implementar programas e planos que ampliem os laços econômicos, políticos e culturais entre as duas regiões.

Seus objetivos oficiais podem ser definidos em termos de gerar condições favoráveis para ampliação e aprofundamento das relações inter-regionais em cooperação econômica e social e a troca de visões sobre desenvolvimento, estratégias de mercado, educação, formação de capital humano, criação de emprego e desenvolvimento social. Assim, na Primeira Reunião de Chanceleres, em março de 2001, definiu-se que o Fórum de Cooperação América Latina - Ásia do Leste (Focalal) ${ }^{2}$ insere-se no contexto do adensamento das relações entre as diferentes regiões do mundo e tem por objetivo preencher lacunas no relacionamento entre as duas regiões.

Dessa forma, o Focalal apresenta forte conteúdo simbólico ao procurar ampliar e aprofundar relações com a região da América Latina, sem a presença dos Estados Unidos. Demonstra não só um crescente interesse asiático pelo espaço latino-americano, mas também a disposição de diferentes Estados, como Japão, China e Coréia do Sul, em participar desse processo. Considera-se que um dos incentivos para a iniciativa Focalal é a percepção asiática de que Alca tende a se efetivar no prazo estabelecido e que, conseqüentemente, pode afetar ou diminuir as possibilidades de inserção da Ásia no espaço latino-americano.

Note-se que essa iniciativa asiática corresponde, de um lado, às demandas latino-americanas de ampliação dos contatos políticos e econômicos com a Ásia e, de outro, soma-se à tentativa regional de desenvolvimento de um bloco asiático, com identidade asiática, através da assim denominada Asean + 3 (Japão, China e Coréia do Sul), sem a presença de países ocidentais. Focalal nada mais é do que a réplica do processo de aproximação, já em desenvolvimento, entre a Ásia e a Europa, o Asem.

\section{CONSIDERAÇÕES FINAIS}

Em decorrência da retomada da atratividade do Brasil pela abertura do mercado e estabilidade financeira e, paralelamente, pela ampliação do mercado através do processo integrativo regional, o Mercosul, percebe-se claramente um crescente interesse asiático pelo Brasil. Esse interesse não é só econômico-comercial, mas igualmente político-estratégico em função da disputa por poder e por mercados que se processa na OMC e em outros fóruns multilaterais. Dessa forma, considera-se que a iniciativa de aproximação entre as duas regiões, através do Focalal, deve gerar a ampliação das potencialidades brasileiras.

Isto é, o presente interesse mútuo, além da busca das complementaridades óbvias em termos de comércio e alianças políticas tanto nos planos bilaterais quanto nos multilaterais, demonstra a vontade política de estreitamento de relações em função da necessidade de estabelecimento de parcerias, de um lado, no processo de distribuição de poder internacional e, de outro, na disputa pela garantia de acesso a mercados.

\section{NOTAS}

1. Em 1991 foram aceitas as participações das três Chinas, sendo as de Taiwan e Hong Kong, como economias não como países. Em 1993, ocorreu a aceitação do México e de Papua-Nova Guiné e, em 1994, do Chile. Rússia, Peru e Vietnã tornaram-se membros plenos em novembro de 1998 . 
2. O Fórum de Cooperação América Latina-Ásia do Leste (Focalal) teve sua reunião inaugural em setembro de 1999, em Cingapura (Reunião de Altos Funcionários). Em agosto de 2000, houve a segunda reunião de Altos Funcionários em Santiago do Chile, seguida em outubro de 2000, pelo primeiro encontro acadêmico. Em março de 2001 realizou-se a primeira reunião de ministros de Relações Exteriores. E, em junho de 2001, dentro desse espírito de aproximação com a Ásia, a Divisão de Ásia e Oceania do Ministério das Relações Exteriores do Brasil realizou o Seminário O Brasil e a Ásia no século XXI: ao encontro de novos horizontes.

\section{REFERÊNCIAS BIBLIOGRÁFICAS}

ARNDT, H.W. "The GATT system, free trade areas and regional cooperation". In: FUKUCHI, T. e KAGAMI, M. (orgs.) Perspectives on the Pacific basin economy: a comparison of Asia and Latin America. Tóquio, Institute of Developing Economies \& The Asian Club Foundation, 1990.

BROOKINGS Northeast Asia Survey, 2000-01.

CHING, F. “An Emerging East Asia”. Far Eastern Economic Review. Hong Kong, Dow Jones, v.162, n.50, december 16, 1999.

CRONE, D. "The politics of emerging Pacific Cooperation". Pacific Affairs. Vancouver, University of British Columbia, v.65, n.1, Spring 1992, p.68-83.

FUKUCHI, T. e KAGAMI, M. (orgs.). Perspectives on the Pacific basin economy: a comparison of Asia and Latin America. Tóquio, Institute of Developing Economies \& The Asian Club Foundation, 1990.

FUNABASHI, Y. "Japan's moment of truth". Survival. Oxford, IISS, v.42, n.4,Winter 2000-01.
GILSON, J. “Japan's role in the Asia-Europe Meeting”. Asian Survey. Berkeley, UCP, v.39, n.5, September/October 1999.

GUTIÉRREZ, H. "La Asean ante el emergente orden mundial: reordenamiento regional y diplomacia colectiva en el Pacifico". Estudios Internacionales. Santiago do Chile, Instituto de Estudios Internationales, v.XXVI, n.101, Enero-Marzo 1993.

KEGLEY, C. "Prospects for prosperity with peace in the Pacific Rim". Carta Internacional. São Paulo, Nupri/USP, n.64, junho 1998.

LEGORRETA, O.M. "Las Organizaciones Multilaterales en la Cuenca del Pacífico". Asia Pacífico 1994. México, El Colégio de México, n.1, 1994.

OLIVEIRA, A.P. "Duas Visões da Apec (Conselho Econômico da ÁsiaPacífico)". Revista Brasileira de Política Internacional. Brasília, Ibri, v.38, n.1, 1995.

RAVENHILL, J. "Apec adrift: implications for economic regionalism in Asia and the Pacific". The Pacific Review. Londres, Taylor \& Francis, v.13, n.2, 2000.

STUBBS, R. "Signing on to liberalization: Afta and the politics of regional economic cooperation". The Pacific Review. Londres, Taylor \& Francis, v.13, n.2, 2000.

SUDO, S. "Japan and Southeast Asia in the Post-Cambodian Conflict Era". Asean Economic Bulletin, Cingapura, Asean, v.11, n.1, July 1994.

Henrique Altemani de Oliveira: Professor do Departamento de Política da Pontificia Universidade Católica de São Paulo, Coordenador Adjunto do Núcleo de Pesquisa em Relações Internacionais da Universidade de São Paulo. 